\title{
Aplicação do Pensamento Sistêmico no Trabalho em Saúde da Família
}

\section{Applying the systemic thinking in the work on family health}

\author{
Hamilton Lima Wagner, Angela Beatriz Papaleo Wagner, Yves Talbot
}

\begin{abstract}
Resumo
Contexto: Trabalhar em saúde da família é abranger um contexto integral da atenção a saúde, em todos os seus aspectos, onde. o referencial biológico se mostra um paradigma inadequado, deixando muitas exceções sem uma explicação adequada. Neste contexto os autores buscaram na teoria sistêmica uma explicação mais abrangente para o seu trabalho junto a comunidade.

Material e Método: Foi feita uma revisão bibliográfica sobre o tema, e aplicado na prática de trabalho da Unidade de Saúde Vila Verde da Prefeitura Municipal de Curitiba um modelo de atendimento sistêmico.

Conclusão: A prática da atenção integral, baseada no paradigma do pensamento sistêmico, parece mudar a relação da equipe de saúde com a comunidade, alterando o modelo de atendimento de demanda a doença para um modelo que além da necessidade sentida promove atividades comunitárias e atende a necessidades correlatas à saúde.
\end{abstract}

\footnotetext{
Abstract

Background: Working in family health requires a holistic framework, which includes all aspects of health. The biological paradigm is not an adequate one because it fails to answer many important questions. The authors present the systemic theory as one that is more applicable to their work in family and community health. Material and Method: The authors review the literature, and apply the systemic theory to their family health practice at Vila Verde Health Unit, Curitiba, Brazil.

Conclusion: The practice of an integrated approach to health, based on the systemic theory, appears to have changed the relationship between the health team and the community. The model of health care delivery has been modified to include health promotion activities and community outreach, in addition to dealing with the health concerns of patients who present at the clinic.
}

\section{Introdução}

Ian McWhiney, em seu artigo "Por Que Nós Precisamos de Um Novo Método Clínico"(12), expressa de um modo claro a evolução do saber médico no decorrer dos séculos. Ao final do mesmo ele pontua a agenda a ser trilhada pelo profissional de hoje para dar uma atenção adequada a população que demanda por serviços de saúde. Se for necessário perceber o outro para entender a maneira de adoecer, se é necessário importar-se com o vivido para que a atenção à saúde se dê com a qualidade esperada nos dias de hoje, mister é compreender o processo em que se instalam as doenças.

Por que a doença surgiu nesta pessoa e neste momento? Esta pergunta, que muitas vezes surge na existência de cada um, tem muita relação com o estilo de viver e as condições sociais nas quais se está envolvido. A compreensão disto leva a pensar na teoria sistêmica introduzida na saúde por Bertalanffy (5) em 1975, e que se baseia em estudos teóricos que datam do inicio deste século.

Segundo esta teoria, todos fazem parte de um sistema que se rege por regras de homeostase e de desenvolvimento, buscando um ponto de equilíbrio entre a manutenção do sistema e seu crescimento. Exemplificando numa família: no mesmo momento em que se estimula uma criança a freqüentar a escola (estímulo de crescimento ou de diferenciação), se orienta a criança a seguir as normas da casa, não aprendendo comportamentos errados com os colegas(estímulo de manutenção das regras de convivência da família). O sistema é dinâmico, sendo o ponto de equilíbrio algo próximo do teórico.

No estudo do processo de adoecer pode-se perceber em que situação a doença se instala numa pessoa, com quais particularidades ocorre nela e de que modo, isto influencia a família e a comunidade onde a pessoa está inserida. $\mathrm{O}$ processo saúde-doença está intimamente relacionado com o modo de viver, com os diferentes tipos de pressão a que as pessoas estão submetidas, alimentos que ingere, características de sua genética e metabolismo, 
além dos relacionamentos com seu meio. $\mathrm{O}$ sistema ao qual se vincula tem suas próprias regras na busca de seu equilíbrio, sendo muitas vezes necessária a disfunção de uma de suas peças para que o todo permaneça conectado este ponto básico é fundamental para que se compreenda as relações que se estabelecem.

Para exemplificar: quando um átomo percle um elétron ele se torna negativo e se une a um sutro para se estabilizar; quando acidose metabólica se instala o organismo responde com taquipneia tentando compensar com uma alcalose respiratória e quando uma pessoa se sente pressionada pela sua família que está funcionando mal ela adoece. Ilustrando melhor, cita-se o caso de uma mulher de 25 anos que casou-se há 3 anos indo residir com seu marido; com sua saída de casa ocorreu que sua mãe e irmã - ambas muito agressivas - entraram em conflito; a fim de contornar o problema ela as convidou para morarem junto e adoeceu (quadro de pânico); com isto as duas pararam de atritar e ficaram cuidando dela, estabilizando a crise familiar.

Compreender o funcionamento das relações humanas, em particular das famílias, é de fundamental importância ao se trabalhar em cuidados primários de saúde - a concepção ecológica que entremeia os conceitos do processo saúde-doença tem íntima relação com o ambiente em que as pessoas estão e com o qual interagem. A percepção destas interações é a chave do sucesso para o profissional envolvido neste tipo de atenção.

Brhum e Cordova(2), definem saúde como a habilidade de viver o seu melhor potencial, lidando com situações de estresse dentro das suas capacidades de reação. Num sistema, a busca da homeostase pode gerar situações de doença, de agressividade ou mesmo de delinqüiência - tudo em função da necessidade de manter o equilíbrio do agrupamento. $\mathrm{O}$ analista que de fora observa a situação, com frequiência pode ter dificuldades de ver o ponto de equilíbrio em que se situa a família em estudo, ou ficar chocado com o tipo de equilíbrio utilizado; mas é de adequada observação e análise que se obterá uma atuação eficiente e eficaz na atenção de cada caso.

Após a revisão de literatura estarão expostos alguns dos resultados do processo de trabalho desenvolvido considerando o pensamento sistêmico, no qual a percepção social em que se insere o indivíduo e sua família, fundamentam a ação. Os resultados ainda preliminares serão foco de estudos posteriores, oferecendo uma visão ampliada do trabalho.

\section{Revisão de Literatura}

A lógica em que as famílias se organizam é a de permanecer unidas, com a manutenção do status quo existente, o que torna delicado lidar com alterações que provoquem mudanças na posição dos seus componentes(13). Quem já não se deparou com crianças que adoecem quando chegam irmãos, com adolescentes envolvidos em drogas ou delinqüindo porque seus pais não lhes dão atenção ou estão em processo de separação(10). Eles nada mais estão fazendo do que gerar situações que buscam retornar ao estado anterior, onde as coisas estavam confortáveis e equilibradas. Situações externas, como desemprego, ocasionam mudança no papel da pessoa dentro da estrutura familiar e levam à perda de referências - o que por sua vez gera instabilidade nos arranjos da estrutura familiar, freqüentemente provocando o aparecimento de patologias - agudas ou crônicas.

No momento em que se compreende que os padrões das famílias atendidas são próprios delas e não dependem do modo de ver ou de viver de quem as atende, ter-se-á dado um passo importante para desenvolver um trabalho voltado à realidade delas, onde se busquem ações que permitam a cada família viver o seu melhor. Este trabalho depende da capacidade de atuação do profissional, do seu treinamento e do grau de desafio que a família representa Doherty e Baird (7) sugerem que há 5 níveis de intervenção na abordagem dos pacientes(modificado):

1. Nível Um: Ênfase Mínima sobre a Família. Este nível básico de envolvimento consiste em lidar com famílias apenas o necessário - por razões práticas ou médico-legais; aqui, a comunicação com as famílias não é vista como habilidade necessária ao médico e sua aquisição não é estimulada. Este nível presumivelmente caracteriza a maior parte do treinamento nas escolas de medicina, onde as questões biomédicas são o único foco consciente de atendimento ao paciente.

2. Nível Dois: Informações e Aconselhamento Médico Contínuo.

Base de Conhecimentos $\Rightarrow$ Primariamente médicos, mais conscientização da dimensão triangular do relacionamento médico-paciente.

Desenvolvimento pessoal $\Rightarrow$ Disposição para engajar pacientes e famílias de uma forma cooperativa.

Habilidades $\Rightarrow 1$. Comunicar regular e claramente achados médicos e opções de tratamento aos membros da família; 2. Indagar questões aos membros da família que façam surgir informações diagnósticas e de tratamento 
relevantes; 3. Escutar atentamente as dúvidas e preocupações dos membros da família; 4 . Aconselhar as famílias sobre como lidar com as necessidades médicas e de reabilitação dos pacientes; 5. Para famílias grandes ou que exigem muito, saber como canalizar a comunicação através de um ou dois membroschave; 6. Identificar ampla disfunção familiar que interfira com o tratamento médico e encaminhar a família a um terapeuta.

\section{Nível Três: Emoções e Apoio.}

Base de Conhecimento $\Rightarrow$ Desenvolvimento familiar normal e reações ao estresse.

Desenvolvimento Pessoal $\Rightarrow$ Conscientização dos próprios sentimentos no relacionamento com o paciente e família.

Habilidades $\Rightarrow 1$. Indagar questões que façam surgir às expressões de preocupação dos membros e sentimentos relacionados à condição do paciente e seus efeitos sobre a família; 2 . Escutar empaticamente as preocupações e sentimentos dos membros da família e informálos sobre a normalidade da situação, quando apropriado; 3. Formar uma avaliação preliminar do nível de funcionamento da família, à medida que se relaciona com os problemas dela; 4. Encorajar os membros da família em seus esforços de enfrentarem a situação como uma família; 5. Adaptar os conselhos médicos às necessidades, preocupações e sentimentos da família; 6. Identificar a disfunção familiar e adaptar uma recomendação de encaminhamento à situação particular da família.

4. Nível Quatro: Avaliação Sistemática e Intervenção Planejada.

Base de conhecimentos $\Rightarrow$ sistema familiar.

Desenvolvimento pessoal $\Rightarrow$ Consciência da própria participação no sistema, incluindo o triângulo terapêutico, o sistema médico, o próprio sistema familiar e os sistemas comunitários mais amplos.

Habilidades $\Rightarrow 1$. Engajar os membros da família, incluindo aqueles relutantes, em uma conferência familiar planejada ou em uma série de conferências; 2. Estruturar uma conferência com uma família com uma comunicação até mesmo fraca, de tal modo que todos os membros tenham uma oportunidade de expressão; 3. Avaliar sistematicamente o nível de funcionamento da família; 4. Apoiar os membros individuais, evitando, ao mesmo tempo, conluios; 5. Redefinir o que a família entende como o "seu" problema de forma a torna-lo mais equacionável; 6. Ajudar os membros da família a perceber suas dificuldades como algo que exige novas formas de esforço cooperativo; 7. Ajudar os membros da família a gerar modos alternativos e mutuamente aceitáveis de lidar com as dificuldades; 8. Ajudar a família a equilibrar seus esforços, calibrando os vários papéis de modo a permitir o apoio sem o sacrifício da autonomia de qualquer um de seus membros; 9 . Identificar a disfunção familiar que jaz além do tratamento primário e orquestrar um encaminhamento, educando a família e o terapeuta acerca do que esperar um do outro.

\section{Nível Cinco: Terapia Familiar.}

Base de Conhecimento $\Rightarrow$ Sistema familiar e padrões pelo qual as famílias disfuncionais interagem com profissionais e outros sistemas de cuidado à saúde.

Desenvolvimento Pessoal $\Rightarrow$ Capacidade para lidar com intensas emoções nas famílias e em si mesmo e para manter o próprio equilíbrio em face da forte pressão dos membros da família ou outros profissionais.

Habilidades $\Rightarrow$ A lista seguinte não é exaustiva de habilidades da terapia familiar, mas é uma relação de várias habilidades que diferenciam o nível cinco de envolvimento de atendimento primário com as famílias. 1. Entrevistar famílias ou membros da família que são bastante difíceis de ser engajados; 2. Gerar eficientemente e testar hipóteses sobre as dificuldades e padrões étnico-culturais da família; 3. Ampliar o conflito na família a fim de romper um impasse familiar; 4. Aliar-se, temporariamente, a um membro da família contra outro; 5. Lidar, construtivamente, com a forte resistência da família às mudanças; 6. Negociar relacionamentos cooperativos com outros profissionais e outros sistemas que estão trabalhando com a família, mesmo quando esses grupos mantêm hostilidade uns com os outros.

Um modo mais direto de definir o conceito de sistemas familiares pode ser buscado em Peggy Papp (2), que define assim as relações do sistema familiar:

"1.Sistema de Família.

A família opera como uma unidade emocional sem vilões, heróis, pessoas boas, pessoas más, saudáveis ou doentes. Os problemas na família resultam do modo que seus membros se relacionam entre si e não do comportamento de qualquer um de seus membros. Qualquer coisa que alguém faça afeta todas as pessoas e dá início a uma cadeia de reações. Se alguém tomar distância, pode estudá-las, observar como transcorrem, como são reforçadas, quem pega tal gancho, e qual o papel de cada um na cadeia de reações.

2.Rotulação.

Cada membro da família eventualmente é programado em um papel específico e rotulado de acordo. Rotular serve à necessidade da família de ter a sua própria identidade, e cada pessoa adquire um papel dentro desta identidade que seja compatível com ela. Cada um participa ao assumir o seu papel e continuá-lo. Muitos 
rótulos são estupefacientes, pois impedem o crescimento e pouco tem a ver com a verdadeira natureza de quem o possui. É possível às famílias entender seu processo de rotulagem e modificá-lo, permitindo que seus membros desenvolvam mais os seus potenciais.

3.Colaboração.

A colaboração entre os membros da família é necessária para que os conflitos continuem. Nenhuma pessoa pode manter uma interação consigo mesma. Estudando como cada membro da família está envolvido no carrossel familiar, pode-se interromper o ciclo pela mudança no comportamento de uma pessoa. Muita frustração pode ser evitada ao se concentrar esforços em mudar a si mesmo, mais do que reclamar dos outros. As pessoas mais felizes são aquelas que tomam mais responsabilidade por sua própria felicidade.

4.Triangulações.

Triangulações tendem a acontecer nas famílias por causa de sua proximidade ou relação intensa. Quando alguém sente-se ferido, bravo, desapontado ou frustrado com outra pessoa da família, e não pode ir contra ela, tende a envolver alguém mais na relação. Pais frequientemente usam seus filhos para maquiarem o que falta entre eles. Crianças também envolvem seus pais em triangulações jogando um contra o outro. Algumas vezes um amigo ou parente é trazido de fora para formar um triângulo. Se uma pessoa do triângulo muda sua posição, todo o triângulo muda. É preferível ter uma relação separada com cada pessoa que não envolva outras pessoas e não forme um triângulo.

5.Fantasmas Familiares.

Os fantasmas familiares são passados de geração em geração. Os pais tendem a assumir a mesma posição emocional que tinham em suas famílias de origem. Eles vêm com préjulgamentos, ansiedades, e expectativas que são trazidas e impostas aos membros da família presente. Se um dos pais compreende como foi programado em sua família de origem e dá passos para mudar isto, ele pavimenta o caminho para fazer o mesmo na família atual.

6.Mudança.

O sistema de família pode mudar se qualquer pessoa tomar uma posição diferente e permanecer nela."

\section{Discussão}

O trabalho em atenção primária que considera o pensamento sistêmico avança na busca de soluções que respeitam as características da comunidade, e em função disto obtém resultados mais consistentes e duradouros. Para que o mesmo seja desenvolvido se faz necessário aprender um novo paradigma de pensamento, onde se reconhece o modo de pensar e agir da comunidade, identificando seus valores e crenças. A comunidade que se percebe identificada e valorizada estabelece parcerias duradouras e isto gera um impacto evidente no resultado do trabalho desenvolvido.

O paradigma biológico, que analisa as causas e faz prognósticos à luz de eventos logicamente encadeados, é inconsistente quando aplicado à comunidade em geral. Se ele é de mais fácil compreensão, por ser reproduzível, também reconhece um grande número de exceções, fruto das variáveis que os diferentes sistemas apresentam(8). A incorporação do paradigma biopsicossocial, tão em moda no falar e tão distante da prática, oferece explicações muito mais coerentes e vinculadas à realidade que vivemos no cotidiano da atenção primária.

A aplicação de cada nível de intervenção dependerá do treinamento, do comprometimento, do tempo disponível pelo profissional e do grau de relacionamento desenvolvido com o paciente e sua família. A capacidade de acesso a cada nível poderá ser muito influenciada pela utilização de ferramentas de apoio ao trabalho: Genograma, Rede Social, Ciclo de Vida das Famílias, F.I.R.O. e P.R.A.C.T.I.C.E(15).

O Genograma é um instrumento que permite graficamente descrever a família, seu padrão de adoecer e de se relacionar. Seu uso facilita a demonstração, tanto para a equipe de saúde como para a própria família, dos padrões de repetição e dos riscos de adoecer mais prevalentes no grupamento em estudo(2).

A Rede Social é um instrumento de percepção das relações familiares e sociais, com o qual se pode compreender o tipo de apoio e correlação que os indivíduos e as famílias tem para enfrentar suas situações de vida. Demonstra à família, de um modo transparente, apoios e deficiências que precisam ser trabalhados no intuito de melhorar o enfrentamento de situações de estresse, além de permitir visualizar os recursos que a comunidade dispõe para apoiar a família em estudo(2).

O Ciclo de Vida das Famílias é um instrumento de percepção das fases de transição da vida familiar; com ele se pode antever momentos onde a saúde se fragiliza e identificar situações que chegam sem ser muito claras, permitindo antecipar as tarefas necessárias para a família em função da situação vivida(2).

A ferramenta F.I.R.O. (Fundamental Interpersonal Relations Orientations) é um instrumento de estudo dos componentes de inclusão, controle e intimidade do grupo, que 
facilita o entendimento das relações interpessoais e em como isto influencia o viver e o adoecer da família. $\mathrm{O}$ instrumento permite vislumbrar a organização e crenças que formam o grupamento e suas linhas de poder, e de que maneira compartilham sentimentos(2).

Em casos onde é necessária uma exploração mais detalhada, utilizando o instrumento P.R.A.C.T.I.C.E. (acróstico em inglês desenvolvido pela Universidade McGill), tem-se um mapa completo do funcionamento e do modo de se relacionar. Com ele se estuda os componentes das queixas identificadas, papéis, afeto, comunicação, tempo no ciclo de vida, passado mórbido e doenças atuais, estratégias de enfrentamento de situações estressantes e apoios, social e familiar ao grupo. $\mathrm{O}$ treinamento em abordagem sistêmica dá ao profissional de cuidados primários a condição única de ter uma visão holística, biopsicossocial, do paciente e de sua família, o que permite ações mais eficientes com um mínimo de agressão e um máximo de satisfação com o trabalho desenvolvido(2).

A abordagem familiar sistêmica compreende a percepção do ambiente onde as pessoas vivem e interagem e em como isto desemboca no processo de adoecer. A compreensão dos conceitos de Rede Social, na percepção de apoios e recursos que estão disponíveis aos pacientes de sua área de trabalho, pode potencializar a ação, garantindo um resultado mais duradouro e consistente. Este diferencial, que agrega a ecologia humana ao trabalho biomédico, é característica fortemente desejável em cuidados primários. A proximidade com a comunidade atendida, suas inter-relações, credos e maneira de enfrentar os seus problemas dá ao profissional envolvido no seu atendimento uma dimensão mais clara das ações a serem desenvolvidas, onde a técnica utilizada leva em conta os recursos disponíveis e a capacidade da população se relacionar com as medidas propostas.

O uso de saúde baseada em evidência, onde se buscam evidências compatíveis com a realidade local, aumenta a qualidade do serviço prestado, freqüentemente com racionalização de custos. A utilização da tecnologia respaldada por trabalhos científicos sérios e criteriosos permite ao profissional de cuidados primários obter grande credibilidade perante seus pares e sua comunidade. Aqui cabe ressaltar a necessidade de produção científica local, de modo a checar a validade das diversas condutas e procedimentos no meio e na população em que se trabalha. O pensamento sistêmico orienta sobre a realidade da comunidade e dá a direção do trabalho; a técnica e o conhecimento científicos são colocados a serviço das necessidades da população.

A abordagem familiar sistêmica compreende várias fases, onde a análise da situação de saúde deve buscar, em primeiro lugar, o diagnóstico preciso da patologia ou situação de saúde que determina a demando ao serviço. A situação vivida pelo paciente é o ponto de partida para a procura de soluções, respaldadas por conhecimentos técnicos adequados, semióticos e clínicos(11).

Num passo seguinte é necessário explorar a situação em que se desenvolveu o processo de adoecer, para, a partir do contexto de vida do paciente e de sua família, planejar ações que visem a sua recuperação e a prevenção de novas enfermidades geradas do mesmo modo. Nesta fase a utilização das ferramentas de trabalho acima citadas terá grande utilidade pois sistematizam a abordagem e dão chaves para o processo de compreensão das relações interpessoais. Aqui os níveis de intervenção sugeridos por Doherty e Baird(7) devem ser considerados à luz das nossas capacidades individuais para trabalhar com as famílias.

Yves Talbot em seu livro Family System Medicine(13), diferencia e identifica bem "Trabalhar com Famílias" de "Terapia de Famílias": trabalhar com famílias significa acompanhá-las ao longo de suas vidas, potencializando suas forças naturais para que, durante o seu desenvolvimento, as famílias e seus membros possam viver o seu melhor potencial. Significa respeitar a sua cultura e seu modo de viver e, ao interagir buscando a promoção da saúde, manter os seus laços e hierarquias. É iatrogênico, na maioria das situações, interferir nas relações familiares, produzindo desequilíbrios sem uma sustentação adequada; isto leva a resultados frustrantes, desestimulando as equipes que não percebem a inconsistência e o dano que podem causar ao tentar atitudes para as quais não foram adequadamente capacitadas. Há que se ter um plano de trabalho para cada grupo a ser atendido, auxiliando-o na construção de sua própria história, cabendo à equipe levar informação clara e de qualidade. O trabalho da equipe deve facilitar a comunicação entre os membros do grupo, apoiar as iniciativas de reflexão sobre suas próprias vidas e permitir que o caminho escolhido seja o caminho da família.

Cabe analisar o treinamento recebido pelos profissionais de cuidados primários para estabelecer um limite individual de abordagem de cada situação, tendo claro que experiências similares às vividas pelo profissional podem ser de manejo difícil - suas próprias reações muitas vezes se sobrepõem às experiências da família 
em foco. É importante também ter presente que a maioria das famílias não necessita de terapia familiar, mas de equipes que as acompanhem ao longo de suas vidas, auxiliando-as a viver e se desenvolver dentro de seu potencial.

O último passo é a capacidade de se comunicar, negociando com o paciente e sua família condutas e alterações nos seus modos de lidar com as situações que provocaram o estado de adoecer. Tarefa - aparentemente singela - é onde freqüentemente falha o técnico de cuidados primários, não ouvindo o paciente quando este coloca seus obstáculos, nem se propondo a construir novos hábitos a partir da realidade do paciente e de sua família(6). Mudanças radicais do modo de vida ou que não considerem a base de conhecimentos e habilidades do paciente e de sua família estão fadadas ao insucesso. É preciso construir a partir da realidade de quem terá de fato que executar a terapêutica e a mudança no estilo de vida: o paciente e sua família(1). Mesmo que não se consigam situações ideais estes acordos são muito mais palpáveis e executáveis obtendo uma taxa muito maior de adesão e sucesso no atendimento aos pacientes.

\section{Resultados}

O trabalho baseado no pensamento sistêmico durante o período de maio de 1999 a maio de 2000, promoveu dentro do trabalho da Unidade de Saúde Vila Verde(US) da Prefeitura Municipal de Curitiba, que atende uma comunidade de 15000 habitantes, alguns resultados muito animadores que listamos a seguir:

1. Alcoolistas: foram realizadas 42 desintoxicações de alcoolistas (índice de recaída de $30 \%$ ), havendo sido criado uma cooperativa de manufatura de artefatos de concreto para alguns alcoolistas e encaminhado discussões familiares de apoio ao grupo e ao paciente. A US mantém um grupo terapêutico de apoio com reuniões semanais, onde são discutidos aspectos relevantes ao hábito e ao funcionamento sistêmico das famílias.

2. Gestantes: o atendimento pré natal incorporou o atendimento as famílias, que passaram a ser envolvidas no acompanhamento a gestante, permitindo a inclusão dos companheiros, filhos a avós no processo, estreitado laços e melhorando o resultado obstétrico. As gestantes e suas famílias são convidadas a participar de um curso de preparação ao parto e aos cuidados do lactente, que inclui aulas de ginástica e vídeos preparatórios - desenvolvidos pela equipe. A taxa de recém natos de risco caiu de $50 \%$ para $27 \%$ no mesmo período.

3. Idosos, hipertensos e diabéticos: o atendimento aos pacientes promoveu uma reclassificação e análise dos casos e iniciado um processo de discussão sobre interesses, dificuldades e a participação das famílias no atendimento aos mesmos. Da discussão surgiu um grupo de ginástica, monitorado pelos próprios pacientes, após um treinamento com professor de educação física, e iniciou-se o processo de formação de cooperativas de trabalho. Hoje funciona uma cooperativa de panificação e correlatos, e uma cooperativa de confecções. A quantidade de medicação fornecida a estes pacientes diminuiu, e o controle dos casos apresentou significativa melhora.

Estes são apenas alguns dos trabalhos desenvolvidos na US em que o pensamento sistêmico norteou as atividades. Outras atividades estão sendo desenvolvidas mas os resultados ainda são incipientes para poderem ser apresentados. Todos os trabalhos aqui citados serão fruto de artigos de avaliação dos resultados.

Mais importante, porém, do que os dados quantitativos, são os dados qualitativos de relação da equipe de saúde com a comunidade alvo. O grupo atendido, com as atividades sistêmicas ainda é pequeno em relação ao universo atendido, mas o diferencial que obtivemos neste trabalho piloto solicita a expansão das pesquisas.

\section{Conclusão}

Trabalhar em saúde da família mostrase muito atraente quando visto pelo paradigma do pensamento sistêmico. Os resultados inicias que estamos documentando são animadores, fazendo com que a equipe de saúde perceba a influência do meio no surgimento e evolução de disfunções a nível individual ou coletivo.

Mudar o modo de pensar e trabalhar, porém, é uma tarefa difícil, que requer tempo e paciência. As pessoas tem a forte tendência de manter o seu passo, dentro de sua zona de conforto, e mudanças só acontecem quando um fato expressivo se cristaliza. O trabalho dentro do novo paradigma ainda precisa de mais documentação, mas os resultados iniciais justificam a busca de novos estudos. 


\section{Bibliografia}

1. BRASIL Ministério da Educação. Para você me educar. Brasília: snt

2. CHRISTIE-SEELY, J. et al. Working with families in primary care. New York: Oxford, 1984.

3. CARTER, Betty et al. As mudanças no ciclo de vida familiar. Porto Alegre: Artes Médicas, 1995.

4. DUNCAN, B et al. Medicina ambulatorial. Porto Alegre: Artes Médicas, 1996.

5. GRASSANO, S. et ail. Abordagem sistêmico integrativa. Curitiba: CD ROM Delôo, 1996.

6. FREIRE, P. Pedagogia da esperança. Rio de Janeiro: Paz e Terra, 1992.

7. McDANIEL, S.H. et al. Terapia familiar médica. Porto Alegre: Artes Médicas, 1994.

8. McWHINNEY, I. R. A textbook of family medicine. New York: Oxford, 1997.

9. MINUCHIN, S. Famílias funcionamento \& tratamento. Porto Alegre:Artes Médicas, 1990.

10. PAPP, P. O processo de inudança. Porto Alegre:Artes Médicas, 1991.

11. ROSSER, W. R., SHAFIR, M. S. Evidence-based family medicine. Toronto: Decker, 1998.
12. STEWART, M. et al. Patient-centered medicine. Thousand Oaks: SAGE, 1995

13. TALBOT, Y. R. et al. Family system medicine. Toronto: Publicola Reg'd, 1991

14. WAGNER, H. L. et al. Abordagem familiar sistêmica. Fazenda Rio Grande: Curso PSF, 1997.

15. WILSON, L. et al. Trabalhando com famílias. Livro de trabalho para residentes.Curitiba: SMS - Curitiba, 1996.

Hamilton Lima Wagner

Médico de Família e Comunidade da Prefeitura Municipal de Curitiba, Mestre em Princípios de Cirurgia, Docente do Instituto inFamilia de Curitiba.

Endereço para correspondência:

Hamilton Lima Wagner

Rua Jaime Veiga, 170 - CEP 80310-570

Curitiba, PR

E-mail: hamiltonw@terra.com.br 